\title{
Assessment of Quantitative Aftershock Productivity Potential in Mining-Induced Seismicity
}

\author{
Maria Kozłowska $^{1}$ (D) and Beata Orlecka-Sikora ${ }^{1}$
}

\begin{abstract}
Strong mining-induced earthquakes exhibit various aftershock patterns. The aftershock productivity is governed by the geomechanical properties of rock in the seismogenic zone, mininginduced stress and coseismic stress changes related to the main shock's magnitude, source geometry and focal mechanism. In order to assess the quantitative aftershock productivity potential in the mining environment we apply a forecast model based on natural seismicity properties, namely constant tectonic loading and the Gutenberg-Richter frequency-magnitude distribution. Although previous studies proved that mining-induced seismicity does not obey the simple power law, here we apply it as an approximation of seismicity distribution to resolve the number of aftershocks, not considering their magnitudes. The model used forecasts the aftershock productivity based on the background seismicity level estimated from an average seismic moment released per earthquake and static stress changes caused by a main shock. Thus it accounts only for aftershocks directly triggered by coseismic process. In this study we use data from three different mines, Mponeng (South Africa), Rudna and Bobrek (Poland), representing different geology, exploitation methods and aftershock patterns. Each studied case is treated with individual parameterization adjusted to the data specifics. We propose the modification of the original model, i.e. including the non-uniformity of $M_{0}$, resulting from spatial correlation of mining-induced seismicity with exploitation. The results show that, even when simplified seismicity distribution parameters are applied, the modified model predicts the number of aftershocks for each analyzed case well and accounts for variations between these values. Such results are thus another example showing that coseismic processes of mining-induced seismicity reflect features of natural seismicity and that similar models can be applied to study the aftershock rate in both the natural and the mining environment.
\end{abstract}

Key words: Mining-induced seismicity, aftershocks, static stress transfer.

Electronic supplementary material The online version of this article (doi:10.1007/s00024-016-1432-7) contains supplementary material, which is available to authorized users.

1 Institute of Geophysics Polish Academy of Sciences, Księcia Janusza 64, 01-452 Warsaw, Poland. E-mail: mkozlow@igf.edu.pl

\section{Introduction}

Aftershock distribution and productivity depend on various factors controlling stress regime in seismogenic layer. The spatial distribution of aftershocks correlates with static (e.g. King et al. 1994) as well as transient dynamic stress changes (e.g. Kilb et al. 2000) caused by the main shock. Aftershocks tend to occur in areas of increased stress; however, they are also observed within the main shock's rupture zone, where the net stress is believed to drop during an earthquake. Such on-fault aftershocks are the result of heterogeneous slip causing heterogeneous coseismic stress change on fault's surface (Helmstetter and Shaw 2006). The duration and productivity of an aftershock sequence were proved to depend on the rock type, its rheological properties and ambient temperature (Ben-Zion and Lyakhovsky 2006; Yang and Bez-Zion 2009). Such a large number of factors controlling the occurrence of aftershocks makes their modeling challenging-so far it was mostly focused on specific aspects of the sequences rather than the overall and detailed prediction. The spatial analyses of aftershocks are based mostly on rate-and-state model of Dieterich (1994), which utilizes coseismic stress changes distribution, or main shock slip models (Das and Henry 2003; Woessner et al. 2006). The time decay of aftershocks is usually considered in terms of Omori-Utsu law (Utsu et al. 1995), which parameters are main shock's magnitude dependence (Hainzl and Marsan 2008).

In order to predict the number of aftershocks directly triggered by the main shock Hainzl et al. (2010) formulated the quantitative earthquakes forecast model based on coseismic static stress changes. According to the authors, the number of aftershocks depends on the long-term tectonic loading of the area and coseismic stress change, similarly as in a rate- 
and-state based model. In the model of Hainzl et al. (2010); however, the long-term tectonic loading is constant in time and equals an average seismic moment released by a background seismicity, calculated analytically based on its frequency-magnitude distribution parameters.

Induced seismicity studies show that strong induced events, similar to natural ones, can be followed by aftershocks representing various patterns. This variability may originate from different geomechanical properties of a rock in a seismogenic zone, differences in the main shock's rupture type, geometry and dynamics, but can also be partly controlled by the exploitation parameters. It was already proven that coseismic stress changes caused by strong mining events can influence the following seismicity distribution (Orlecka-Sikora 2010; Orlecka-Sikora et al. 2012; Kozłowska et al. 2015). Modeling of the seismicity rate, based on Coulomb stress changes and the rate-and-state friction law, can be successfully applied to induced seismicity data and help to predict the spatial and temporal distribution of aftershocks of strong mining events (Kozłowska et al. 2015). However, in contrast to natural seismicity, the mining loading is irregular and changes in time. The timevarying exploitation progress and geometry entails transient character of mining-induced seismicity and a tendency to form clusters correlated in space and time with mining activities (e.g. Gibowicz 1997, 2006; Orlecka-Sikora and Lasocki 2002; Kozłowska 2013). The magnitude distribution of mining seismicity is complex and often multi-modal (e.g. Lasocki 2008). Observed focal mechanisms are directly coupled to the mining geometry, and thus vary across the seismogenic zone (e.g. Hasegawa et al. 1989), which stands in contrast to uniform focal mechanism distributions assumed while estimating the average scalar seismic moment release per earthquake (Catalli et al. 2008).

Despite all these unique features, substantially different from the properties of the tectonic earthquake process, there is some evidence that models tested for natural seismicity give satisfying results also when applied to the mining environment (e.g. Kozłowska et al. 2015). To test the Hainzl et al. (2010) model and to study the aftershock productivity potential in mining-induced seismicity we applied the proposed forecast to three mining catalogs. They represented different mines, mining methods and rock properties to consider various aftershock patterns. To account for spatial correlation of mininginduced seismicity with exploitation we propose the non-uniform seismic moment release based on the background seismicity probability density function (PDF).

The procedures applied after strong earthquake in many mines, for example in Polish copper mines, aimed at minimizing the aftershocks' risk, rely mainly on tremor's energy, and thus, do not take into account the detailed characteristics of observed seismicity. The modeling presented in this study may contribute to better assessing the aftershock's risk and contribute in improving the post-earthquake procedures applied in mines.

\section{Model}

According to Hainzl et al. (2010) the number of directly triggered aftershocks can be calculated based on the long-term average of seismic moment released per earthquake, $M_{0}$, in the studied seismogenic volume. $M_{0}$ is estimated from the frequency-magnitude distribution parameters: $b$-value, the minimum and maximum magnitude, $M_{\min }$ and $M_{\max }$ :

$M_{0}=10^{9.1+1.5 M_{\min }} \frac{b}{1.5-b} \frac{10^{(1.5-b)\left(M_{\max }-M_{\min }\right)}-1}{1-10^{-b\left(M_{\max }-M_{\min }\right)}}[\mathrm{Nm}]$.

Here, the $M_{0}$ value is assumed constant in space and long-term seismicity is assumed to follow the Gutenberg-Richter distribution. The number of triggered aftershocks $N_{\mathrm{a}}$ is calculated by summing $K$ values of static stress change, $\triangle C F F$, each one representing separate subvolume $\mathrm{d} V$, over the whole analyzed volume, according to equation:

$$
N_{a} \approx \frac{\mathrm{d} V}{M_{0}} \sum_{k=1}^{K} \Delta C F F \cdot H[\Delta C F F],
$$

where $H[\triangle C F F]$ denotes the Heaviside function: $H[\triangle C F F]=1$ for $\triangle C F F \geq 0$ and 0 elsewhere. The stress change is expressed in terms of a Coulomb failure function, $\Delta C F F=\Delta \tau+\mu \bullet(\Delta \sigma+\Delta p)$, where $\tau$ is the shear stress in the slip direction, $\sigma$ is 
the normal stress, $\mu$ is the coefficient of friction and $p$ is the pore pressure. The positive change of static stress moves the fault towards failure, and thus increases the probability of aftershock.

In our study we calculate $\triangle C F F$ using Coulomb 3.0 software (Lin and Stein 2004; Toda et al. 2005), assuming zero pore pressure. The software requires rectangular source geometry input. In each analyzed case we divided the area surrounding the main shock into $K$ subvolumes, where $K$ varied between cases according to the area size and location accuracy. The area chosen depends on the source size and aftershock distribution. Also, in each studied case, we removed the $\triangle C F F$ result outliers, that is, the calculation points with extreme values of $\triangle C F F$ resulting from the computation limitations. The cut-off value was estimated empirically based on $\triangle C F F$ distribution for each analyzed case separately as $15 \%$ of the maximum value. However, in each case there were only few outlying points, so the operation did not influence the final results significantly. Both $\mathrm{d} V$ and $\Sigma \triangle C F F$ values for each analyzed case are given in supplemental Table S1.

The original model assumes $M_{0}$ value constant in space, which can be a good approximation for tectonic plate boundaries, but does not apply in case of mininginduced seismicity. Therefore, in this study we propose the modification of the model taking into account the distribution of seismically active zones in the considered area. It is described in detail in the section on Rudna mine, where such a method was applied.

\section{Data and Quantitative Modeling of Aftershocks}

\subsection{Mponeng Mine}

On December 27th, 2007 a $M_{\mathrm{w}} 2.2$ seismic event occurred in Mponeng mine, one of the deep gold mines in South Africa. The main shock occurred within an almost vertical diorite dike intersecting a gold-bearing reef and had a normal faulting focal mechanism (Fig. 1). The seismic moment tensor was determined from 12 in-mine borehole stations located in Mponeng and nearby TauTona mines: 10 threecomponent geophones and two weak-motion accelerometers. The main shock was followed by a micro-aftershock sequence comprising more than
25,000 events during the following 7 days. Detection and location of a part of these events was made possible by an acoustic sensors' network installed in Mponeng mine within the JAGUARS project (Japanese-German Underground Acoustic Emission Research in South Africa) held in 2007-2009. The network was capable of recording seismic events with $M_{\mathrm{w}}<0.5$ (Kwiatek et al. 2010). Kozłowska et al. (2015), in their study on modeling of seismicity rate changes caused by the $M_{\mathrm{w}} 2.2$ seismic event, analyzed the aftershock activity in a confined area surrounding the main shock's hypocenter. The authors determined the background seismicity rate $r_{\mathrm{m}}$ from available data preceding the main shock and, based on that, estimated the aftershock sequence duration $t_{\mathrm{a}}$ as the time until the aftershock rate returned to the background rate. The obtained values were 4.33 events/h (with standard error $=0.3$ ) and 5 days, respectively. The complete aftershock catalog with $M_{\mathrm{c}}-3.4$, confined to the chosen area and time span of 5 days, contained 1603 events. This number was distorted by the lack of first $4.5 \mathrm{~h}$ of recording caused by overloading of the hard disk (Naoi et al. 2011). To account for the missing events we estimated their number based on the Omori's law function derived in the study of Kozłowska et al. (2015). After adding the estimated number of missing events to the catalog it contained 2937 events.

The location error of aftershocks in Mponeng mine did not exceed $5 \mathrm{~m}$, which enabled detailed comparison of the modeled and observed distribution of aftershocks, performed by Kozłowska et al. (2015) in six defined depth intervals (i.e. $3380-3460 \mathrm{~m} ; 3460-3480 \mathrm{~m}$; 3480-3500 m; $\quad 3500-3520 \mathrm{~m} ; \quad 3520-3540 \mathrm{~m}$; 3540-3560 m). In present study we followed this spatial division of hypocentral area to perform a more detailed analysis of $\triangle \mathrm{CFF}$ influence on the number of aftershocks. For each interval, the $\triangle \mathrm{CFF}$ distribution was calculated and applied in Eq. (2), resulting in an individual estimation of the number of aftershocks (Fig. 1). The extreme values of $\Delta \mathrm{CFF}>1.4 \mathrm{MPa}$ were set to 0 to avoid overestimation of the number of aftershocks in the area closest to the main shock's hypocenter. To compensate for this operation, the aftershocks observed in these areas were excluded from the total number. The rest of parameters used in Eq. (1) were set the same for the whole study area. $M_{\min }$ was applied as completeness magnitude for the whole 


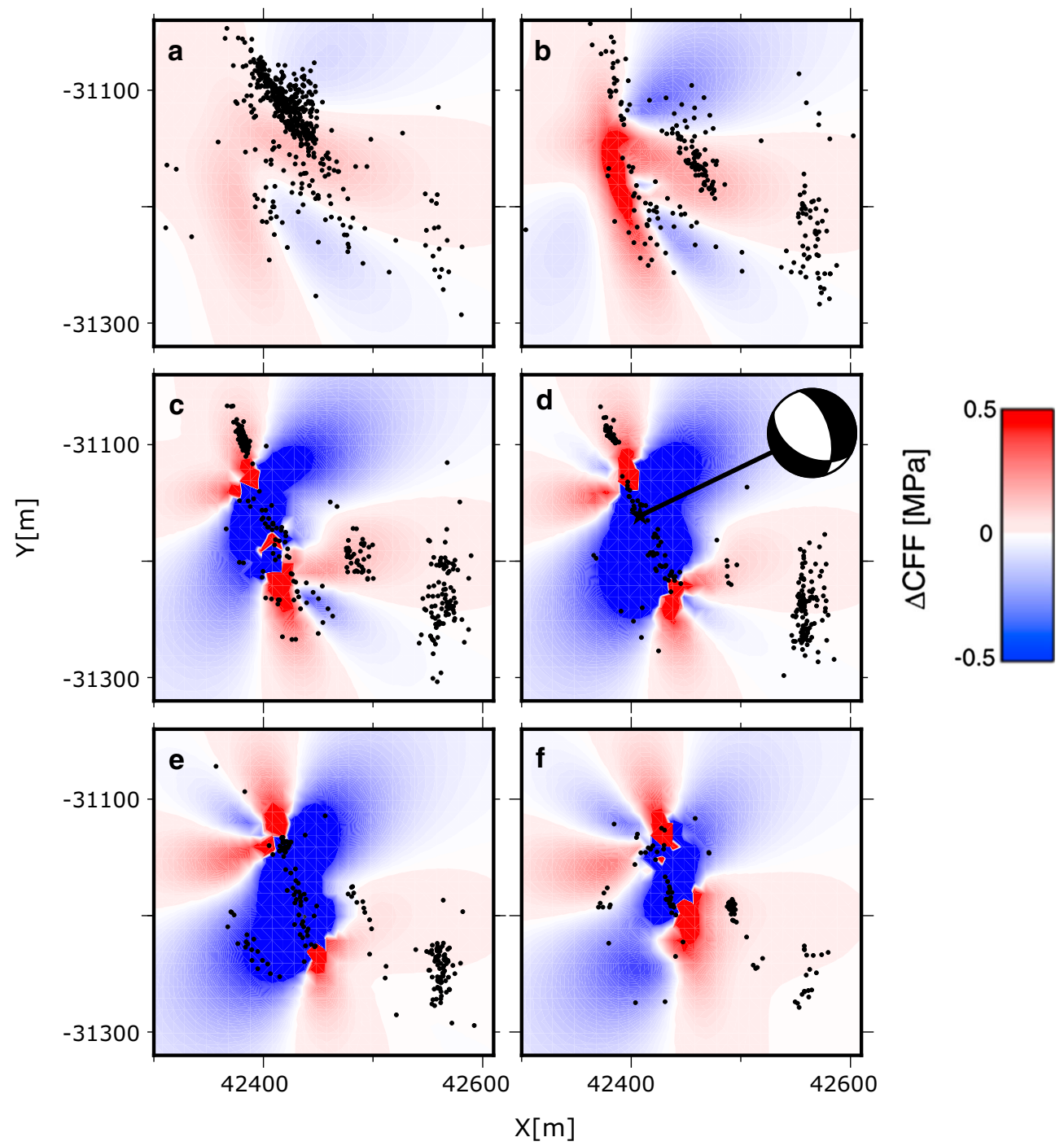

Figure 1

The $\triangle \mathrm{CFF}$ computed for six depth intervals a-f. D interval contains the main shock's hypocenter. Focal mechanism solution is presented as a beach ball in D interval and aftershocks above completeness level $M_{\mathrm{c}}$ are presented as black dots

catalog, i.e. $M_{\min }=M_{\mathrm{c}}=-3.4$ (Kwiatek et al. 2010). Since the available continuous seismic catalog from Mponeng mine covered only 11 days, reliable estimation of the maximum credible magnitude $M_{\max }$ and $b$ value was not possible. Thus, $M_{\max }$ was set as a maximum magnitude recorded in Mponeng mine in the period 2007-2010, i.e. $M_{\max }=4.2$ (Boettcher, personal information). We made an attempt to calculate the $b$ value for the available short catalog, both undeclustered and declustered, and got values of 0.73 and 0.79 , respectively, which resulted in highly underestimated number of aftershocks for each depth interval (Table 1).
Kwiatek et al. (2010) estimated $b$-values for both aftershock sequences and post-blasting activity and found values of 1.26 and between 1.1 and 1.21, respectively. However, the magnitude-frequency distributions of both aftershocks and post-blasting periods were dominated by small events which increased $b$ values and should not be treated as representative for general long-term seismicity in studied area. Ogasarawa et al. (2002) analyzed the catalog recorded in Mponeng mine in 1996 and reported $a b$-value of 0.9 for seismicity before $M_{\mathrm{w}} 2.0$ event. Boettcher et al. (2009) analyzed data from 12 years of seismic observation of TauTona 
Table 1

The observed and estimated number of aftershocks of analyzed main shocks

\begin{tabular}{|c|c|c|c|c|}
\hline \multirow[t]{2}{*}{ Depth interval $[\mathrm{m}]$} & \multirow{2}{*}{$\begin{array}{l}\text { No. of observed events in } t_{\mathrm{a}} \\
\text { time (not including events in } \\
\text { extreme CFF areas) }\end{array}$} & \multicolumn{3}{|c|}{ No. of estimated aftershocks } \\
\hline & & $b$-value $=0.79$ & $b$-value $=0.85$ & $b$-value $=0.9$ \\
\hline \multicolumn{5}{|c|}{ Mponeng mine: $t_{\mathrm{a}}=5$ days, $M_{\min }=-3.4, M_{\max }=4.2$} \\
\hline A: $[3380 ; 3460)$ & 512 & 66 & 162 & 338 \\
\hline B: $[3460 ; 3480)$ & 229 & 30 & 74 & 155 \\
\hline C: $[3480 ; 3500)$ & 302 & 23 & 56 & 112 \\
\hline D: $[3500 ; 3520)$ & 231 & 19 & 47 & 98 \\
\hline E: $[3520 ; 3540)$ & 184 & 21 & 52 & 109 \\
\hline F: $[3540 ; 3560)$ & 102 & 24 & 58 & 122 \\
\hline$\Sigma$ for the whole area & 1560 & 183 & 449 & 934 \\
\hline $\begin{array}{l}\text { Total no. of events (including } \\
\text { missing } 4.5 \mathrm{~h} \text { ) }\end{array}$ & 2894 & & & \\
\hline $\begin{array}{l}\text { No. of triggered aftershocks } \\
\text { (not including background seismicity) }\end{array}$ & 2374 & $\begin{array}{l}183 \text { ( } 8 \% \text { of } \\
\text { obszerved number })\end{array}$ & $\begin{array}{l}449(19 \% \text { of } \\
\text { observed number })\end{array}$ & $\begin{array}{l}934(39 \% \text { of } \\
\text { observed number })\end{array}$ \\
\hline
\end{tabular}

Rudna mine: $t_{\mathrm{a}}=4$ days, $M_{\min }=1.2, M_{\max }=4.26$

\begin{tabular}{|c|c|c|c|}
\hline \multirow[t]{2}{*}{ Total no. of events } & \multirow[t]{2}{*}{18} & \multicolumn{2}{|l|}{$b$-value $=0.85$} \\
\hline & & $\begin{array}{l}\text { Uniform seismic } \\
\text { moment release }\end{array}$ & Spatially variable seismic moment release \\
\hline $\begin{array}{l}\text { No. of triggered aftershocks } \\
\quad \text { (not including background seismicity) }\end{array}$ & 16 & $\begin{array}{l}21 \text { (131\% of observed } \\
\text { number) }\end{array}$ & 16 (100\% of observed number) \\
\hline \multicolumn{4}{|c|}{ Bobrek mine: $t_{\mathrm{a}}=0$ days, $M_{\min }=1.5, M_{\max }=4.3$} \\
\hline \multirow[t]{2}{*}{ Total no. of events } & 0 & $b$-value $=1.52$ & \\
\hline & & $\begin{array}{l}\text { Uniform seismic } \\
\text { moment release }\end{array}$ & Spatially variable seismic moment release \\
\hline $\begin{array}{l}\text { No. of triggered aftershocks } \\
\quad \text { (not including background seismicity) }\end{array}$ & 0 & 5 & 3 \\
\hline
\end{tabular}

In case of the Mponeng mine event the separate numbers are given for each six depth intervals and the estimated numbers are given for four models using different $b$-values. The italics' rows show final comparison of observed and estimated number of triggered aftershocks for each analyzed case

mine, adjoining the Mponeng mine. The authors estimated $b$-value for seismicity recorded during low level of mining activity as close to 0.85 . In our modeling we applied the three mentioned $b$-values of $0.79,0.85$ and 0.9 to test their influence on the results. The final value was the one which resulted in the most accurate fit of the model to the observed number of aftershocks, $b=0.9$.

The area chosen for the analysis was relatively small, centered around mining tunnels and active mining front and covered mined out parts. Thus, we could assume that the whole studied area had been seismically active and that the average seismic moment release was constant in space. The final result of the modeling was the sum of number of events estimated for each of six depth intervals. To compare results with the observed number of aftershocks above $M_{\mathrm{c}}$, first we confined the catalog to time span of 5 days, then we added estimated number of missing aftershocks and finally we subtracted the estimated number of background events to obtain the theoretical number of triggered aftershocks. The quantitative results of modeling are presented in Table 1.

\subsection{Rudna Mine}

On March 19th, 2013 a $M_{\mathrm{w}} 4.2$ seismic event occurred in a mining panel of Rudna mine, one of the 
copper ore mines in Legnica-Głógów Copper District (LGCD) in southwestern Poland. The mine's seismicity has been monitored by both underground and surface seismic networks. At the time of the 19 March event the underground network, maintained by Mining Geophysical Survey, was composed of 32 vertical component seismometers. The surface seismic network, maintained by the Institute of Geophysics, Polish Academy of Sciences, was composed of 4 short-period seismometers. Both networks' data were used to determine source parameters of the strong mining event; however, results did differ both in terms of the focal mechanism and spectral parameters (Lizurek et al. 2015). The analysis has been extended by data from the regional seismic network which helped to reveal the complex rupture history of the $M_{\mathrm{w}} 4.2$ earthquake (Rudziński et al. 2016). It started as a thrust faulting event along a preexisting normal fault and continued as a stronger collapse. Based on a 14-year catalog of seismicity from the mining panel where the $M_{\mathrm{w}} 4.2$ event had occurred, the completeness magnitude was estimated using the Modified Goodness-of-fit test (Leptokaropoulos et al. 2013) as $M_{\mathrm{c}}=1.2$. The background seismicity rate for the complete catalog was determined as $r_{\mathrm{m}}=0.4$ event/day (with standard error $=0.01$ ). The resulting $t_{\mathrm{a}}$ time was estimated as 4 days. In this time 18 events above the completeness magnitude occurred within the limited area around the main shock's hypocenter, not including one postblasting event.

The parameters of Eq. (1) were estimated based on the 14 years' catalog. $M_{\min }$ was applied as the completeness magnitude for the whole catalog, i.e. $M_{\text {min }}=M_{\mathrm{c}}=1.2$. $M_{\max }$ was estimated using the Kijko-Sellevol generic formula (Kijko and Sellevoll 1989), $M_{\max }=4.26$. We found the $b$-value $=0.85$.

Following Rudziński et al. (2016), we assumed that the $M_{\mathrm{w}} 4.2$ main shock consisted of two subevents. The moment tensor (MT) of the first subevent was determined based on in-mine network using FOCI software (Lizurek et al. 2015; Kwiatek 2013), whereas the MT of the second subevent was based on the regional network, using the Kiwi tool inversion platform (Heimann 2011; Cesca et al. 2013) and the local velocity model of Poland, GM2003 (Grad et al. 2003). The first $M_{\mathrm{w}} 3.6$ subevent was dominated by double-couple (DC) component of reverse faulting with strike $=309^{\circ}$, dip $=47^{\circ}$ and rake $=96^{\circ}$ and source radius of $223 \mathrm{~m}$ and slip of $0.13 \mathrm{~m}$ (Fig. 2). The second subevent, $M_{\mathrm{w}} 4.2$, was dominated by an implosive component and represented a collapse (Rudziński et al. 2016). To calculate the Coulomb stress changes distribution we modeled the complex earthquake as two collocated events, one with a pure shear mechanism of reverse faulting, and the second as an implosive source (Fig. 2). To parameterize the tensile subevent to a rectangular fault, we used its DC component and determined the fault plane parameters as: strike $=250^{\circ}$, dip $=49^{\circ}$ and rake $=-84^{\circ}$. However, as the DC component represented only $3 \%$ of the full MT, the applied fault geometry was just a rough approximation of a real source. The tensile source radius was set as a mean value from the results of spectra of 8 broadband stations, obtained using Brune (1970) source model. The displacement value was estimated from the seismic moment tensor of a tensile source in isotropic media (Aki and Richards 2002):

$$
M_{i j}=u S\left[\lambda v_{k} n_{k} \delta_{i j}+\mu\left(v_{i} n_{j}+v_{j} n_{i}\right)\right],
$$

where $u$ is the mean slip, $S$ is the fault area, $\lambda$ and $\mu$ are Lame's constants both equal to $2.2 \times 10^{4} \mathrm{MPa}, v$ and $n$ are the dislocation direction and fault normal,

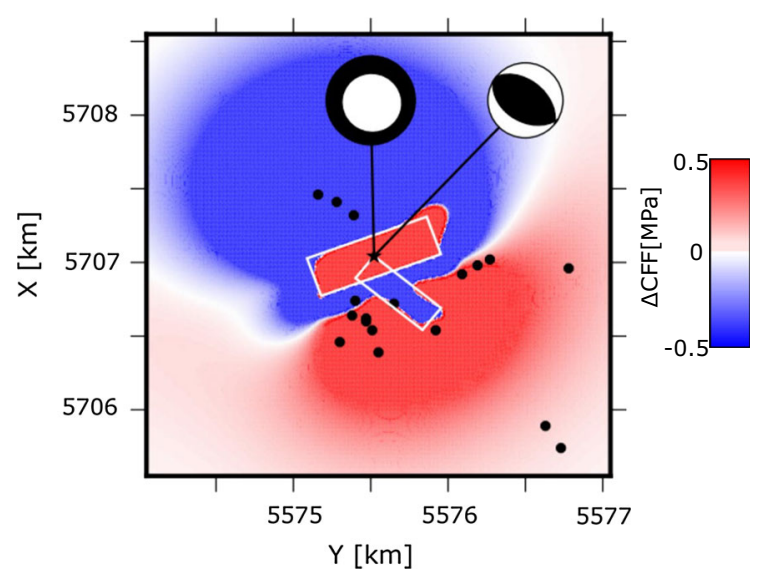

Figure 2

The $\Delta$ CFF distribution due to 19.03 .2013 event in Rudna mine. The main shock is represented by two subevents: DC focal mechanism solution is shown for the first subevent, zero trace focal mechanism for the second subevent. Both subevents' fault planes are marked with white rectangles. Aftershocks and main shock epicenters are marked with black points and star, respectively 
respectively, expressed in terms of strike, dip, rake and slope angle $\alpha$, which describes the tensility of the source (Vavryčuk 2001). Then, the mean displacement was decomposed into tensile and shear component.

The rectangular fault planes of both events were parameterized based on source radii and assuming the fault length to width ratio equal to 2 . We used the Poisson ratio value of $v=0.25$, the apparent coefficient of friction equal $\mu=0.8$ and shear modulus of $G=22 \mathrm{GPa}$ (Orlecka-Sikora 2010). We performed the analysis in the $3 \mathrm{~km} \times 3 \mathrm{~km}$ area surrounding main shock's hypocenter, at the mean depth of aftershocks $-785 \mathrm{~m}$. The receiver plane for $\triangle C F F$ calculation was chosen as the dominant plane of aftershocks, almost parallel to the orientation of the main cracks. The calculation depth range was set to $80 \mathrm{~m}$, which corresponded to the depth range of observed aftershocks. The extreme values of $\Delta \mathrm{CFF}>18 \mathrm{MPa}$ were set to 0 to avoid overestimation of number of aftershocks in the area closest to main shock's hypocenter. The final observed number of triggered aftershocks was estimated by subtracting the background seismicity rate from the actual observed number of events in $t_{\mathrm{a}}$ time of 4 days.

The studied area of Rudna mine covered not only mining section where the $M_{\mathrm{w}} 4.2$ event took place but also other active and mined out sections, as well as a great volume of intact rock, making the assumption of uniform distribution of seismic moment incorrect. Therefore, we decided to identify the intact area and assign to it the zero value of $M_{0}$. We did that by spatially smoothing the seismicity observed in all mining sections in the study area using 2-D nonparametric kernel estimator of the earthquake occurrence PDF (Silverman 1986), the procedure used and described in Kozłowska et al. (2015). The applied smoothing parameter was equal to horizontal location uncertainty, $h=25 \mathrm{~m}$, and smoothing was performed in the same grid as $\triangle C F F$ calculation. The number of aftershocks was calculated by the sum

$$
N_{a} \approx \frac{\mathrm{d} V}{M_{0}} \sum_{k=1}^{K} p \cdot \Delta C F F \cdot H[\Delta C F F],
$$

where an additional parameter $p$ was introduced to account for zero background seismicity, such that $p=1$ for subvolumes with seismicity PDF $>0$ and $p=0$ for subvolumes with seismicity $\mathrm{PDF}=0$.

Figure 3 presents the applied procedure.

The comparison of the observed and estimated number of triggered aftershocks, applying both uniform and non-uniform $M_{0}$, is presented in Table 1 .

\subsection{Bobrek Mine}

On December 16th, 2009 a $M_{\mathrm{L}} 3.7$ seismic event occurred in Bobrek coal mine in Upper Silesia, Poland, during exploitation of panel 3 of coal seam no. 503. At that time the seismicity of the panel was monitored by a seismic network consisting of 12 short-period seismometers -7 vertical and 5 threecomponent sensors. The $M_{\mathrm{L}} 3.7$ event occurred at great depth below the mined seam, over $500 \mathrm{~m}$, which suggested that its mining-tectonic character is linked to the local tectonic structure of the Bytom syncline (Kozłowska et al. 2016). According to the authors the event had a reverse faulting mechanism on an almost vertical plane, with a very high doublecouple (DC) component. The seismic catalog of events accompanying exploitation of panel 3 covered a 15 months' period between April 2009 and July 2010. In January 2010 the seismic network was developed and gradually a few additional stations were added. However, the analysis of the completeness magnitude for the catalog before and after the network's development did not reveal any change in the $M_{\mathrm{c}}$ value-for both periods, and thus, also for the whole catalog, it was equal to $M_{\mathrm{c}}=1.5$. The background seismicity rate for the complete catalog was determined as $r_{\mathrm{m}}=0.8$ event/day (with standard error $=0.07$ ). This value was not exceeded during the 5 days following the main shock, so we concluded that the event was not followed by any aftershocks.

The parameters of Eq. (1) were estimated based on a 15 months' catalog. $M_{\min }$ was applied as the completeness magnitude for this catalog, $M_{\min }=M_{\mathrm{c}}=1.5$, and $M_{\max }$ as the maximum credible magnitude, both estimated using the same methods as in the case of Rudna mine catalog, resulting in $M_{\max }=4.3$. We found the $b$ value $=1.52$. We applied the moment tensor of the 

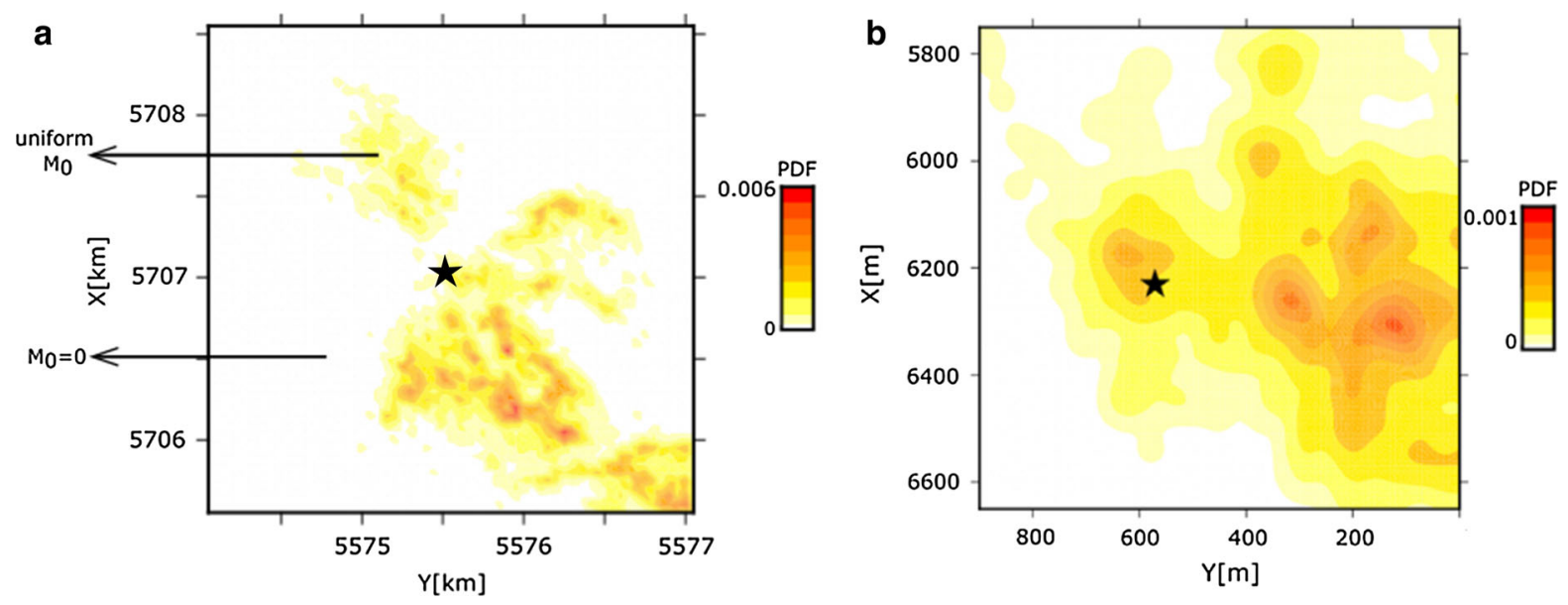

Figure 3

The probability density function (PDF) distribution of background seismicity in study area of a Rudna mine and $\mathbf{b}$ Bobrek mine. White parts indicate areas with no background seismicity where zero $\mathrm{M}_{0}$ value is assumed. Stars indicate main shocks' epicenters

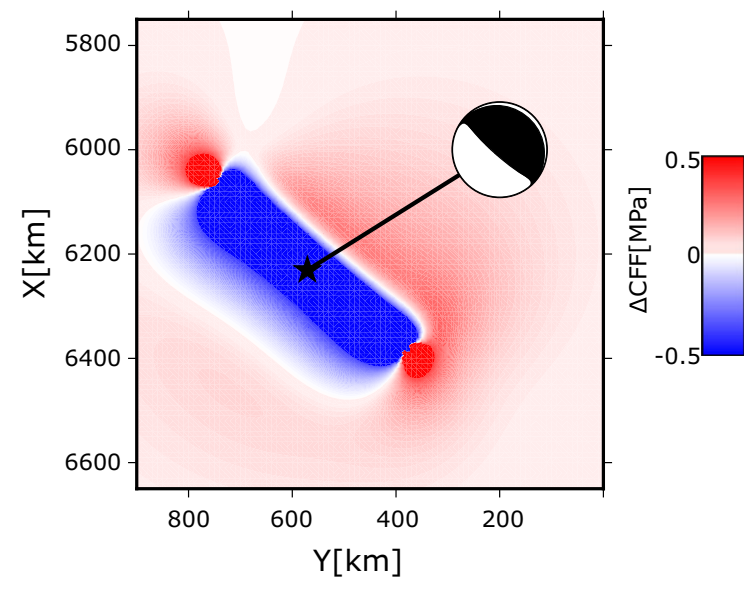

Figure 4

The $\triangle \mathrm{CFF}$ distribution due to 16.12 .2009 event in Bobrek mine. The main shock is represented by a star. There were no aftershocks observed for this event

$M_{\mathrm{L}} 3.7$ event presented in Kozłowska et al. (2016) (Fig. 4). The $\triangle C F F$ distribution was calculated using the Poisson ratio value of $v=0.24$, the apparent coefficient of friction equal to $\mu=0.46$ and shear modulus of $G=2.2 \mathrm{GPa}$ (Kozłowska et al. 2016). We performed the analysis in the $0.9 \mathrm{~km} \times 0.9 \mathrm{~km}$ area covering the hypocentral area and exploited panel. The receiver plane for $\triangle C F F$ calculation was chosen as the dominant plane of deep events following the $M_{\mathrm{L}} 3.7$ event in western part of the panel. To set the calculation depth range we analyzed the depth distribution of events which occurred during a week preceding and a week following the $M_{\mathrm{L}} 3.7$ event, below the mined seam. 50\% of analyzed events occurred in a depth range of $150 \mathrm{~m}$, so we applied this value as the calculation depth range. The extreme values of $\triangle C F F>2.8 \mathrm{MPa}$ were set to 0 to avoid overestimation of the number of aftershocks in the area closest to main shock's hypocenter. The study area covered not only panel 3 but also mined out panel 2 and yet intact rock where panel 4 has been planned. We thus determined the aseismic area using the method described in previous section (Fig. 3). The comparison of the observed and estimated number of triggered aftershocks is presented in Table 1.

\section{Discussion}

Three mining cases analyzed in this paper represent different characteristics of aftershock sequences-from the numerous micro-aftershock sequences observed in Mponeng mine, through over a dozen of aftershocks in Rudna mine, to zero aftershocks in Bobrek mine. The applied modeling followed the general trend of varying aftershock numbers; however, it did not give accurate results.

Based on the Mponeng case, we can see that the theoretical number of aftershocks strongly depends 
on the $b$-value applied in the model. Unfortunately, $b$ value of mining-induced seismicity is estimated based on the catalog which often contains intense but transient increase of post-blasting activity. Because of low magnitude of post-blasting events they artificially increase the rate of weak seismicity, thus increasing the $b$-value. Similar problems apply to aftershocks in natural seismicity catalogs. What is more, it has been proven that induced seismicity, mining-induced in particular, does not follow the Gutenberg-Richter frequency-magnitude distribution (e.g. Urban et al. 2015; Lasocki 2001), which is evidence of the complexity of the physical phenomenon governing seismicity in mines (Kijko et al. 1987). However, there are numerous studies utilizing the power law to mining sequences to study their frequency-magnitude characteristics (e.g. Kwiatek et al. 2010; Boettcher et al. 2009; Nuannin et al. 2005; Holub 1996). Nevertheless, determining the $b$ value in this study is a simplification applied to run the model. The comparison of the observed and theoretical number of aftershocks, obtained using different $b$-values, can help us to choose the most appropriate value approximating the character of a mine's seismicity. In the case of Mponeng mine, the application of $b$-value $=0.9$, stated by Ogasarawa et al. (2002), resulted in the most accurate results.

The $M_{\mathrm{w}} 2.2$ Mponeng mine event triggered numerous micro-aftershocks which were recorded only due to the very sensitive seismic network. Kozłowska et al. (2015) showed that some of these aftershocks were associated with heterogeneities in the main shock's rupture, and some, especially at greater distance from the main shock's hypocenter, were directly induced by coseismic stress changes. This fact can explain the underestimated number of theoretical aftershocks predicted in this study. The model aims at predicting only the number of aftershocks directly triggered by Coulomb stress change, not accounting for those caused by heterogeneous slip. The observed number of aftershocks is the combination of the both types of events, and thus is greater than the predicted number.

The modification of the model by introducing the non-uniformity of applied $M_{0}$ improved the results in both Rudna and Bobrek mine cases. The spatially uniform background seismicity assumption, valid in case of natural seismicity, does not apply to most of mining-induced data and thus, may lead to overestimation of a number of triggered aftershocks. Mininginduced seismicity is the effect of rock mass disturbance causing high stress concentration which magnitude in the area of exploitation is much higher than coseismic stress changes (e.g. Pytel 2003; Yasitli and Unver 2005; Kozłowska et al. 2016). It means that seismicity in mines occurs almost exclusively close to exploitation areas. Therefore, it is justified to assume that in the rock mass undisturbed by exploitation, even when it is affected by coseismic stress changes, no aftershocks are produced.

The fact that few or no aftershocks were observed for stronger events in Rudna and Bobrek mines does not mean that none of these events were followed by on-fault weak aftershocks. The relatively high completeness magnitudes determined for both datasets $\left(M_{\mathrm{c}}=1.2\right.$ and 1.5 respectively) let us only study strong aftershocks. The Rudna mine event was followed by 16 triggered aftershocks and so was the number of estimated events, making the model's prediction accurate. We have to keep in mind, though, that the source model of a tensile subevent used to resolve the $\triangle \mathrm{CFF}$ distribution is just an approximation of the real source, and that it could influence the calculated stress changes and, consequently, the theoretical number of aftershocks.

There were no aftershocks observed in Bobrek mine; however, the modeling predicted 3. The lack of aftershocks is surprising taking into account the fact that the event was triggered rather than induced and associated with local tectonic structure of Bytom syncline. Kozłowska et al. (2016) showed that mining activity triggered seismicity in tectonically vulnerable seismogenic layer a few hundred meters below exploitation.

All three analyzed cases represent different mining and geological settings. Both in Mponeng and Rudna mines the seismogenic zone is composed of high-strength rock with shear moduli of 24 and 22 $\mathrm{GPa}$, respectively. Both main shocks were followed by aftershocks, in contrast to the Bobrek mine earthquake. The geomechanical parameters of the seismogenic zone in Bobrek mine were much lower than in the other two cases, $G=2.2 \mathrm{GPa}$. This fact indicates that the seismogenic layer, composed mainly of sandstones and shales, may be more prone 
to deformation than stress accumulation. This may in turn explain the lack of aftershocks.

\section{Conclusions}

In this paper we performed the quantitative modeling of aftershocks resulting from coseismic static stress changes for strong events in three underground mines. Each of the analyzed cases represented different aftershocks characteristics and the modeling results reflected these changes. Despite the fact that mining-induced seismicity does not obey Gutenberg-Richter frequency-magnitude distribution, the average scalar seismic moment, determined based on this distribution, appeared to be a good representation of a long-term level of seismicity in each analyzed case. The proposed model's modificationthe inclusion of non-uniformity into $M_{0}$ distribution, clearly improved the results. Thus, the model may be used as a tool to estimate the aftershock productivity potential. However, future analyses performed for induced seismicity should account for the complexity of the magnitude distribution.

The observed differences in aftershock productivity, evident especially for Rudna and Bobrek mines' events, may reflect the differences in geomechanical properties of the seismogenic zone rocks. High-strength rock accumulates more stress and tends to release it in a main shock-aftershocks sequence, whereas low strength rock releases all the accumulated stress during the rupture that produces the main shock.

Open Access This article is distributed under the terms of the Creative Commons Attribution 4.0 International License (http://creativecommons.org/licenses/by/4.0/), which permits unrestricted use, distribution, and reproduction in any medium, provided you give appropriate credit to the original author(s) and the source, provide a link to the Creative Commons license, and indicate if changes were made.

\section{REFERENCES}

Aki, K., \& Richards, P. G. (2002). Quantitative seismology (2nd ed.). Sausalito: University Science Books.
Ben-Zion, Y., \& Lyakhovsky, V. (2006). Analysis of aftershocks in a lithospheric model with seismogenic zone governed by damage rheology. Geophysical Journal International, 165, 197-210. doi:10.1111/j.1365-246X.2006.02878.x.

Boettcher, M. S., McGarr, A., \& Johnston, M. (2009). Extension of Gutenberg-Richter distribution to $M_{\mathrm{w}}-1.3$, no lower limit in sight. Geophysical Research Letters. doi:10.1029/2009GL038080.

Brune, J. (1970). Tectonic stress and the spectra of seismic shear waves from earthquakes. Journal Geophysical Research, 75, 4997-5009. doi:10.1029/JB075i026p04997.

Catalli, F., Cocco, M., Console, R., \& Chiaraluce, L. (2008). Modeling seismicity rate changes during the 1997 UmbriaMarche sequence (central Italy) through rate- and state-dependent model. Journal Geophysical Research, 113, B11301. doi:10. 1029/2007JB005356.

Cesca, S., Rohr, A., \& Dahm, T. (2013). Discrimination of induced seismicity by full moment tensor inversion and decomposition. Journal of Seismology, 17(1), 147-163. doi:10.1007/s10950-0129305-8.

Das, S., \& Henry, C. (2003). Spatial relation between main earthquake slip and its aftershock distribution. Reviews of Geophysics, 41, 1013. doi:10.1029/2002RG000119.

Dieterich, J. H. (1994). A constitutive law for rate of earthquake production and its application to earthquake clustering. Journal Geophysical Research, 99, 2601-2618. doi:10.1029/93JB02581.

Gibowicz, S. J. (1997). An anatomy of a seismic sequence in a deep gold mine. Pure and Applied Geophysics, 150, 393-414.

Gibowicz, S. J. (2006). Seismic doublets and multiplets at the Polish coal and copper mines. Acta Geophysica, 54, 142-157. doi:10.2478/s11600-006-0014-y.

Grad, M., Jensen, S. L., Keller, G. R., Guterch, A., Thybo, H., Janik, T., et al. (2003). Crustal structure of the Trans-European suture zone region along POLONAISE'97 seismic prole P4. Journal Geophysical Research. doi:10.1029/2003JB002426.

Hainzl, S., Brietzke, G. B., \& Zöller, G. (2010). Quantitative earthquake forecast resulting from static stress triggering. Journal Geophysical Research, 115, B11311. doi:10.1029/ 2010JB007473.

Hainzl, S., \& Marsan, D. (2008). Dependence of the Omori-Utsu law parameters on main shock magnitude: Observations and modeling. Journal Geophysical Research, 113, B10309. doi:10. 1029/2007JB005492.

Hasegawa, H. S., Wetmiller, R. J., \& Gendzwill, D. J. (1989). Induced seismicity in mines in Canada: An overview. Pure and Applied Geophysics, 129, 423-453.

Heimann, S. (2011). A robust method to estimate kinematic earthquake source parameters. $\mathrm{PhD}$ thesis, University of Hamburg.

Helmstetter, A., \& Shaw, B. E. (2006). Relation between stress heterogeneity and aftershock rate in the rate-and-state model. Journal Geophysical Research, 111, B07304. doi:10.1029/ $2005 J B 004077$.

Holub, K. (1996). Space-time variations of the frequency-energy relation for mining-induced seismicity in the Ostrava-Karvina Mining District. Pure and Applied Geophysics, 146, 265-280.

Kijko, A., Drzęźla, B., \& Stankiewicz, T. (1987). Bimodal character of the distribution of extreme seismic events in polish mines. Acta Geophysica Polonica, 35, 157-166.

Kijko, A., \& Sellevoll, M. A. (1989). Estimation of earthquake hazard parameters from incomplete and uncertain data files. Natural Hazards, 3, 1-13. 
Kilb, D., Gomberg, J., \& Bodin, P. (2000). Triggering of earthquake aftershocks by dynamic stresses. Nature. doi:10.1038/ 35046046.

King, G. C. P., Stein, R. S., \& Lin, J. (1994). Static stress changes and the triggering of earthquakes. Bulletin of the Seismological Society of America, 84, 935-953.

Kozłowska, M. (2013). Analysis of spatial distribution of mining tremors occurring in Rudna Copper Mine (Poland). Acta Geophysica, 61(5), 1156-1169. doi:10.2478/s11600-013-0137-x.

Kozłowska, M., Orlecka-Sikora, B., Kwiatek, G., Boettcher, M. S., \& Dresen, G. (2015). Nanoseismicity and picoseismicity rate changes from static stress triggering caused by a $M_{\mathrm{w}} 2.2$ earthquake in Mponeng gold mine, South Africa. Journal of Geophysical Research: Solid Earth. doi:10.1002/2014JB011410.

Kozłowska, M., Orlecka-Sikora, B., Rudziński, Ł., Cielesta, S., \& Mutke, G. (2016). Atypical evolution of seismicity patterns resulting from the coupled natural, human-induced and coseismic stresses in a longwall coal mining environment. International Journal of Rock Mechanics and Mining Sciences, 86, 5-15. doi:10.1016/j.ijrmms.2016.03.024.

Kwiatek, G. (2013). http://www.induced.pl/projekty/foci (in Polish).

Kwiatek, G., Plenkers, K., Nakatani, M., Yabe, Y., Dresen, G., JAGUARS-Group (2010). Frequency-magnitude characteristics down to magnitude -4.4 for induced seismicity recorded at Mponeng gold mine, South Africa. Bulletin of the Seismological Society of America doi:10.1785/0120090277.

Lasocki, S. (2001). Quantitative evidences of complexity of magnitude distribution in mining-induced seismicity: Implications for hazard evaluation. In: G., van Aswegen, R.J., Durrheim, W.D., Ortlepp (Eds.), Rockbursts and Seismicity in Mine: Dynamic rock mass response to mining, SAIMM S27, Johannesburg, 543-550.

Lasocki S. (2008). Some unique statistical properties of the seismic process in mines. In: Proceedings of the 1st Southern Hemisphere international rock mechanics symposium, vol. 1: mining and civil. Nedlands, Western Australia: Australian Centre for Geomechanics; p. 667-678.

Leptokaropoulos, K. M., Karakostas, V. G., Papadimitriou, E. E., Adamaki, A. K., Tan, O., \& İnan, S. (2013). A homogeneous earthquake catalogue for Western Turkey and magnitude of completeness determination. Bulletin of the Seismological Society of America, 103(5), 2739-2751.

Lin, J., \& Stein, R. S. (2004). Stress triggering in thrust and subduction earthquakes and stress interaction between the southern San Andreas and nearby thrust and strike-slip faults. Journal Geophysical Research, 109, B02303. doi:10.1029/ 2003 JB002607.

Lizurek, G., Rudziński, Ł., \& Plesiewicz, B. (2015). Mining induced seismic event on an inactive fault. Acta Geophysica, 63(1), 176-200. doi:10.2478/s11600-014-0249-y.

Naoi, M., Nakatani, M., Yabe, Y., Kwiatek, G., Igarashi, T., \& Plenkers, K. (2011). Twenty thousand aftershocks of a very small (M 2) earthquake and their relation to the main shock rupture and geological structures. Bulletin of the Seismological Society of America. doi:10.1785/0120100346.
Nuannin, P., Kulhanek, O., Persson, L., \& Askemur, T. (2005). Inverse correlation between induced seismicity and $b$-value, observed in the Zingruvan Mine, Sweden. Acta Geodynamics et Geomaterialia, 2(140), 5-13.

Ogasawara, H., Sato, S., Nishii, S., Kawakata, H., \& The Research Group for Semi-Controlled Earthquake Generation Experiments in South African Deep Gold Mines. (2002). Temporal variation of seismic parameters associated with an $M_{\mathrm{w}} \sim 2$ event monitored at a $100 \sim 200 \mathrm{~m}$ distance. In H. Ogasawara, T. Yanagidani, and M. Ando (Eds.), Seismogenic Process Monitoring, Balkema, Rotterdam.

Orlecka-Sikora, B. (2010). The role of static stress transfer in mining induced seismic events occurrence, a case study of the Rudna mine in the Legnica-Glogow Copper District in Poland. Geophysical Journal International, 182, 1087-1095. doi:10. 1111/j.1365-246X.2010.04672.X.

Orlecka-Sikora, B., \& Lasocki, S. (2002). Clustered structure of seismicity from the Legnica-Głogów copper district, Publications of the Institute of Geophysics, Polish Academy of Sciences, M-24(340), 105-119.

Orlecka-Sikora, B., Lasocki, S., Lizurek, G., \& Rudziński, Ł. (2012). Response of seismic activity in mines to the stress changes due to mining induced strong seismic events. International Journal of Rock Mechanics and Mining Sciences, 53, 151-158. doi:10.1016/j.ijrmms.2012.05.010.

Pytel, W. (2003). Rock mass-mine workings interaction model for Polish copper mine conditions. International Journal of Rock Mechanics and Mining Sciences, 40, 497-526. doi:10.1016/ S1365-1609(03)00028-5.

Rudziński, Ł., Cesca, S., \& Lizurek, G. (2016). Complex Rupture Process of the 19 March 2013, Rudna Mine (Poland) induced seismic event and collapse in the light of local and regional moment tensor inversion. Seismological Research Letters, 87(2), 274-284. doi:10.1785/0220150150.

Silverman, B. W. (1986). Density estimation for statistics and data analysis, monographs on statistics and applied probability. Monographs on Statistics and Applied Probability Series, p. 175, Chapman and Hall, London.

Toda, S., Stein, R. S., Richards-Dinger, K., \& Bozkurt, S. B. (2005). Forecasting the evolution of seismicity in southern California: Animations built on earthquake stress transfer. Journal Geophysical Research, 110, B05S16. doi:10.1029/2004JB003415.

Urban, P., Lasocki, S., Blascheck, P., do Nascimento, A. F., Van Giang, N., \& Kwiatek, G. (2015). Violations of GutenbergRichter relation in anthropogenic seismicity. Pure and Applied Geophysics. doi:10.1007/s00024-015-1188-5.

Utsu, T., Ogata, Y., \& Matsu'ura, R. S. (1995). The centenary of the Omori formula for a decay of aftershock activity. Journal of Physics of the Earth, 43, 1-33.

Vavryčuk, V. (2001). Inversion for parameters of tensile earthquakes. Journal Geophysical Research, 106, 16339-16355.

Woessner, J., Schorlemmer, D., Wiemer, S., \& Mai, P. M. (2006). Spatial correlation of aftershock locations and on-fault main shock properties. Journal Geophysical Research, 111, B08301. doi:10.1029/2005JB003961. 
Yang, W., \& Bez-Zion, Y. (2009). Observational analysis of correlations between aftershock productivities and regional conditions in the context of a damage rheology model. Geophysical Journal International, 177, 481-490. doi:10.1111/j. 1365-246X.2009.04145.x.
Yasitli, N. E., \& Unver, B. (2005). 3D numerical modeling of longwall mining with top-coal caving. International Journal of Rock Mechanics and Mining Sciences, 42, 219-235. doi:10.1016/ j.ijrmms.2004.08.007.

(Received April 21, 2016, revised November 11, 2016, accepted November 15, 2016, Published online December 5, 2016) 